Research Article

\title{
Contact Forces in a Screw Feeding Process
}

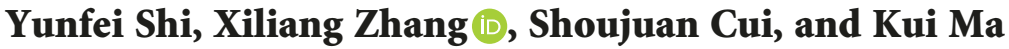 \\ School of Mechanical Engineering, Jiangsu University, Zhenjiang 212013, China \\ Correspondence should be addressed to Xiliang Zhang; zhangxl@ujs.edu.cn \\ Received 3 November 2017; Revised 6 July 2018; Accepted 22 July 2018; Published 19 August 2018 \\ Academic Editor: Charles C. Sorrell \\ Copyright (c) 2018 Yunfei Shi et al. This is an open access article distributed under the Creative Commons Attribution License, \\ which permits unrestricted use, distribution, and reproduction in any medium, provided the original work is properly cited. \\ The contact force between particles is analysed in this paper. Firstly, theoretical analysis is carried out based on the Hertz-Mindlin (no \\ slip) model. Secondly, the normal force and tangential force are, respectively, simulated in single/double-flight screw feeders with the \\ discharging device at three rotating speeds $(60 \mathrm{rpm}, 90 \mathrm{rpm}$, and $120 \mathrm{rpm})$ using different diameter particles $(3 \mathrm{~mm}, 5 \mathrm{~mm}$, and \\ $7 \mathrm{~mm}$ ) by the extended distinct element method (EDEM) software. Finally, the simulation results show that the particle diameter has \\ the biggest impact on average contact force in the feeding process. This research provides theoretical basis for the study of the rule of \\ bulk material movement in the screw feeder and the development of the high-precision feeding machine.
}

\section{Introduction}

The screw feeder is widely used in the short distance transportation of bulk material in agricultural and biological engineering [1-6]. It is mainly composed of trough, bin, and screw shaft. It has the advantages of simple structure, airtight conveying, and controllable feeding quantity. However, the instability and the periodic fluctuation of the feeding quantity limit its industrial application. Nowadays, the contact force of granular matter inside the feeder in the feeding process has raised global scholars' interests. For example, Zheng et al. [7-9] studied the contact force between viscoelastic ellipsoidal particles based on the contact mechanics and finite element method. Fernandez et al. [10] considered the material forms of motion from the hopper to trough and simulated the variable pitch and variable diameter screw conveyor using the discrete element method (DEM). Yang and Cheng [11] investigated the contact force and coordination number distributions for granular materials under breakage during one-dimensional compression using the DEM. However, there are few reports on the contact force between particles in feeding process.

The motion of bulk material in trough is a discrete nonclassical medium movement. It is important to study the contact force between particles and its changes [12]. The changes of normal force between particles reflect the friction resistance changes, and the changes of tangential force between particles reflect the sliding ability changes, which can all indirectly reflect characteristics of the particle motion in the screw feeder. Meanwhile, the DEM has been widely used in the industrial engineering [13-15]. DEM has been successfully applied in simulating and predicting the process of conveying granular solids. Although the linear springdashpot-slider system is the most common contact force model, more detailed contact force models have been applied, which is based on the classical Hertz's theory for the normal direction and on simplifications of the model developed by Mindlin and Deresiewicz for the tangential direction [16-19].

Therefore, this paper studies the contact force between particles in the screw feeding system with the discharging device. The simulations are, respectively, carried out in single-flight and double-flight screw feeders at three rotating speeds $(60 \mathrm{rpm}, 90 \mathrm{rpm}$, and $120 \mathrm{rpm}$ ) when feeding different diameter particles $(3 \mathrm{~mm}, 5 \mathrm{~mm}$, and $7 \mathrm{~mm})$.

\section{Theoretical Analysis for Contact Force}

Throughout this paper, the Hertz-Mindlin (no slip) model is considered. As shown in Figure 1, the particle 1 contacts the particle 2 at the point $\mathrm{C}$ and relatively moves. The dashed line indicates the initial position, while the solid line indicates the final position. The coupler is utilized to simulate 


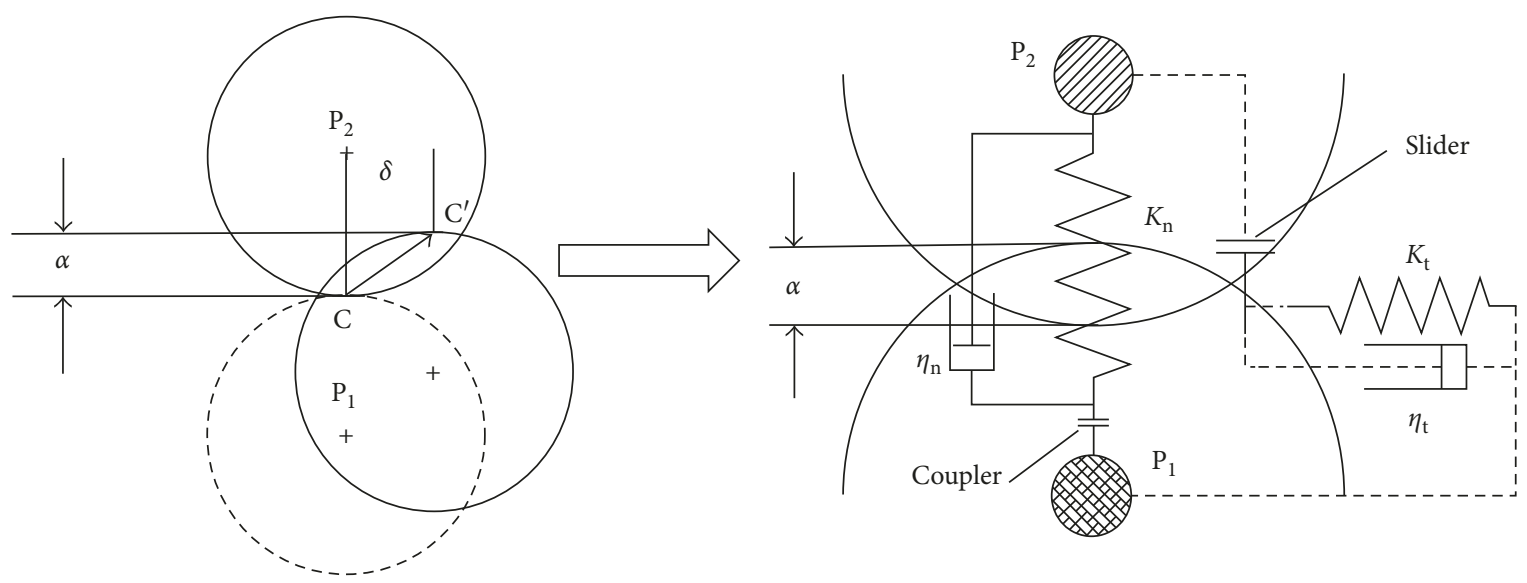

FIgURe 1: Particle contact mode.

the relationship of paired particles. If the tangential force $F_{t}$ exceeds the yield value, the two particles will slide under the normal force $F_{\mathrm{n}}$ and the frictional resistance, which is simulated by the slider damper [20].

The normal and tangential decomposition of the motion of particle contact process is carried out. We decompose the vibrating motion of particle contact process in the normal and tangential directions. The normal equation of motion of the particle is given as follows [21]:

$$
\frac{m_{1,2} d^{2} u_{\mathrm{n}}}{d t^{2}}+\frac{c_{\mathrm{n}} d u_{\mathrm{n}}}{d t}+K_{\mathrm{n}} u_{\mathrm{n}}=F_{\mathrm{n}} .
$$

The tangential vibrational motion of the particle contact process is characterized by tangential sliding and particle rolling. The tangential equation of motion of the particle and the rolling are given by

$$
\begin{gathered}
\frac{m_{1,2} d^{2} u_{\mathrm{t}}}{d t^{2}}+\frac{c_{\mathrm{t}} d u_{\mathrm{t}}}{d t}+K_{\mathrm{t}} u_{\mathrm{t}}=F_{\mathrm{t}}, \\
\frac{I_{1,2} d^{2} \theta}{d t^{2}}+\left(\frac{c_{\mathrm{t}} d u_{\mathrm{t}}}{d t}+K_{\mathrm{t}} u_{\mathrm{t}}\right) s=M,
\end{gathered}
$$

where $m_{1,2}$ is the equivalent mass; $I_{1,2}$ is the equivalent moment of inertia; $s$ is the turning radius; $u_{\mathrm{n}}$ and $u_{\mathrm{t}}$ are the normal and tangential relative displacements, respectively; $\theta$ is the angle of rotation; $F_{\mathrm{n}}$ and $F_{\mathrm{t}}$ are the normal and tangential components, respectively; $M$ is the external torque of particles; $K_{\mathrm{n}}$ and $K_{\mathrm{t}}$ are the normal and tangential coefficients of elasticity, respectively; $c_{\mathrm{n}}$ and $c_{\mathrm{t}}$ are the normal and tangential damped coefficients.

The friction between the particles affects the tangential sliding of the particles and the rolling of the particles. The sliding model has the limit condition of the tangential sliding and rolling of the particles:

$$
F_{\mathrm{t}}=\mu K_{\mathrm{n}} u_{\mathrm{n}} \operatorname{sgn}\left[K_{\mathrm{t}} \frac{u_{\mathrm{t}}+d \theta}{2}\right],
$$

where $\mu$ is the particle friction coefficient and sgn[] is the symbolic function is

$$
\operatorname{sgn}(x)= \begin{cases}1, & x \geq 0 \\ -1, & x \leq 0\end{cases}
$$

\section{The Screw Feeding Discrete Element Model}

In order to improve the stability of discharging quantity, the screw feeder is installed the "discharging device" at the outlet. The "discharging device" is fixed to the trough and does not rotate with the screw shaft. It contains six thin baffles, which uniformly distributes on the sleeve. As shown in Figure 2, the diameter of the screw and the screw shaft are 65 millimeter and 20 millimeter, respectively. Thickness of the flight is 3.5 millimeter. The inner diameter of the trough is 67 millimeter, and the single-flight screw pitch is 70 millimeter. The doubleflight screw pitch is 35 millimeter.

The feeding process of the single-flight and double-flight screws is simulated at three rotating speeds $(60 \mathrm{rpm}, 90 \mathrm{rpm}$, and $120 \mathrm{rpm}$ ) with 3-, 5-, and 7-millimeter diameter particles. It is important to note that the feeding method in this paper is turning the screw shaft $60^{\circ}$ and then stopping for $0.5 \mathrm{~s}$, and it is repeated.

The coefficient of restitution, Poisson's ratio, and other parameters are shown in Tables 1 and 2 [22]. In order to control the running time, fixed time step is set as $20 \%$ of the Rayleigh time step and the grid length is twice of the radius of the particle. As shown in Figure 3, the simulation data of contact force are collected when the choke section (black box area) filling rate is full.

3.1. The Contact Force between Particles at Different Speeds. Figure 4 shows the average of the contact force distribution between particles at three different speeds in the single-flight screw feeding using 5-millimeter diameter particles. Figure 4 shows that the average normal forces are stronger than the average tangential forces in the same moment. Meanwhile, there is an average contact force obviously stronger than others at the speed of $60 \mathrm{rpm}$. The reason is that the average overlap between particles is biggest at the speed of $60 \mathrm{rpm}$. 


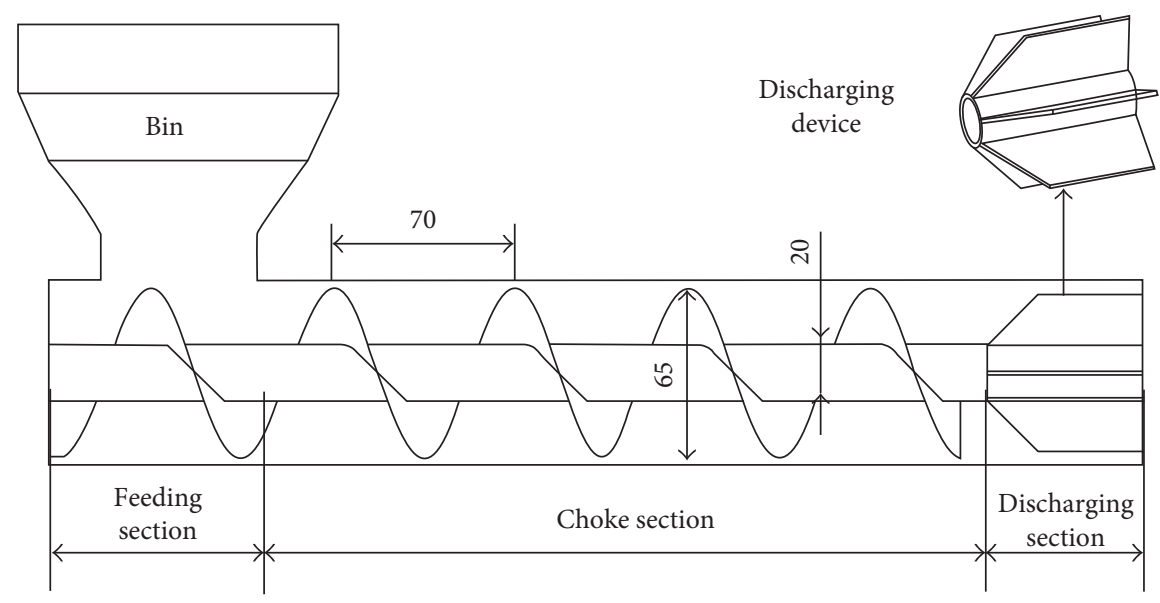

(a)

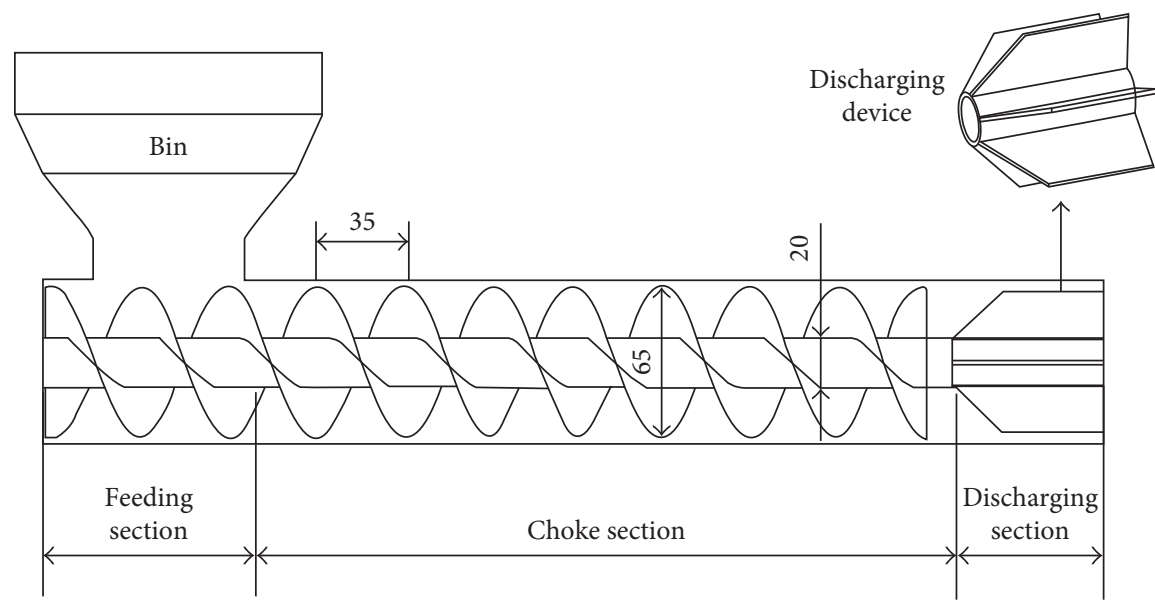

(b)

Figure 2: The geometry model of the screw feeder.

3.2. The Contact Force between Particles in Single/DoubleFlight Screw Feeders. The average of the contact force distribution between particles in single/double-flight screw feeders using 5-millimeter diameter particles is as shown in Figure 5. The average contact forces in the single-flight screw feeding at the speed of $120 \mathrm{rpm}$ are stronger than those in the double-flight screw feeding, causing the particles to be tumble more easily in the single-flight screw feeding. The reason is that the discharging device has larger space hindrance function in the single-flight screw feeding.

3.3. The Contact Force between Particles with Different Diameters. Figure 6 shows the average of the contact force distribution between particles with three different diameters at the speed of $60 \mathrm{rpm}$ in the single-flight screw feeding. As the diameter is increased, the strongest average contact force increased so that the smaller particles easily maintain motion morphology.
TABLE 1: Material parameters used in the simulation.

\begin{tabular}{lccc}
\hline Material & $\begin{array}{c}\text { Poisson's } \\
\text { ratio }\end{array}$ & $\begin{array}{c}\text { Shear } \\
\text { modulus } \\
(\mathrm{Pa})\end{array}$ & $\begin{array}{c}\text { Density } \\
\left(\mathrm{kg} / \mathrm{m}^{3}\right)\end{array}$ \\
\hline $\begin{array}{l}\text { Glass } \\
\text { bead }\end{array}$ & 0.25 & $2.4 e+10$ & 3000 \\
Steel & 0.31 & $8.1 e+10$ & 7850 \\
\hline
\end{tabular}

\section{Conclusions}

In conclusion, the average contact force is investigated using both theoretical analysis and simulations. Among the three factors in this paper, the biggest impact on average contact force is the particle diameter, which leads the biggest impact on motion morphology in the progress of the screw feeding. In industrial production, in order to get accurate feeding quantity, the screw feeder which has faster rotating speed, 
TABLE 2: Contact parameters used in the simulation.

\begin{tabular}{lccc}
\hline Interaction & Coefficient of restitution & Coefficient of static friction & Coefficient of rolling friction \\
\hline Particle-particle & 0.1 & 0.6 & 0.01 \\
Particle-boundary & 0.2 & 0.5 & 0.01 \\
\hline
\end{tabular}

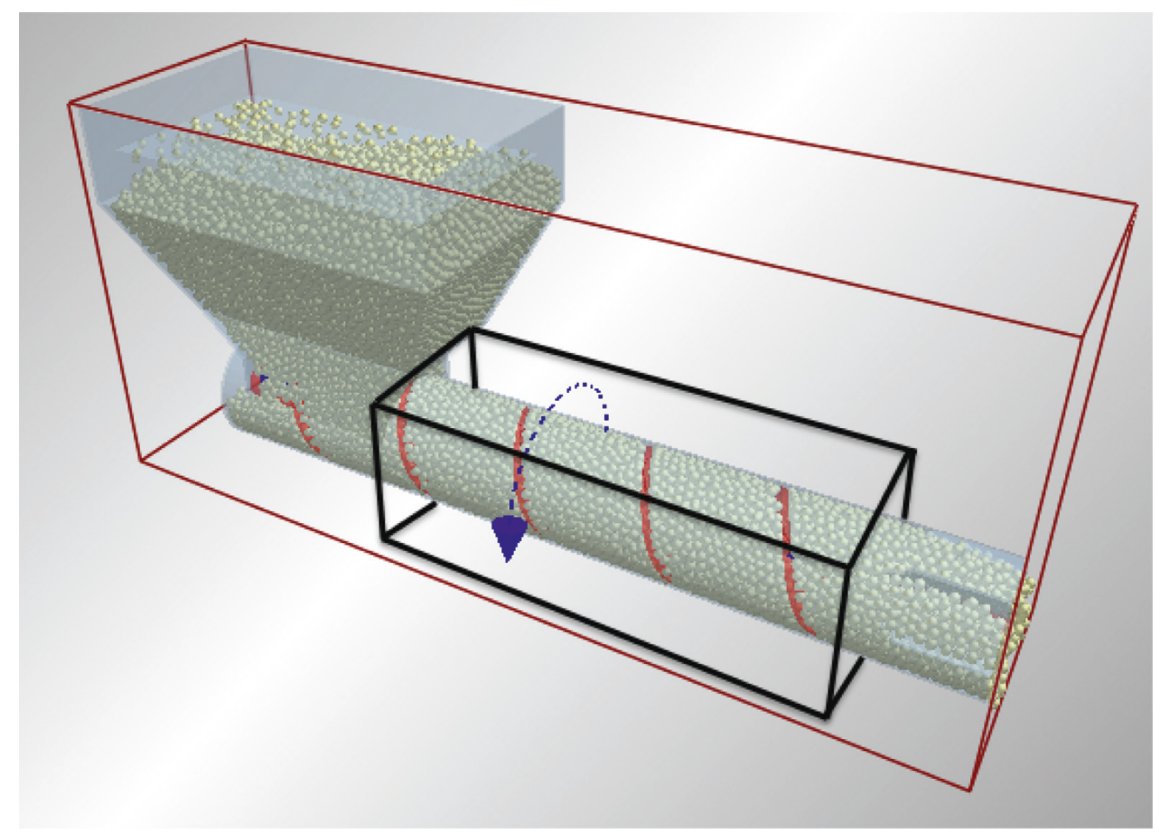

Figure 3: The simulation images of single-flight screw feeder.

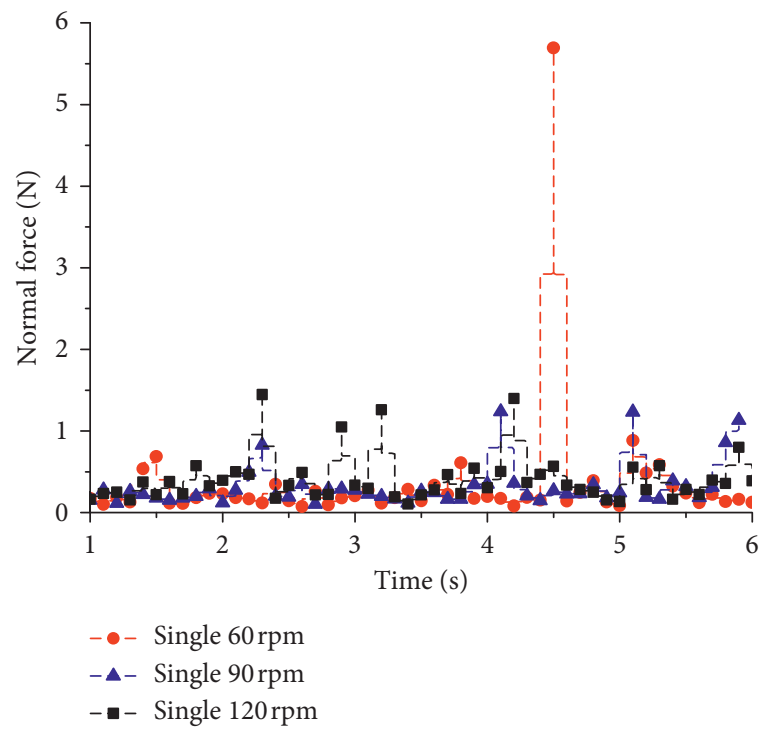

(a)

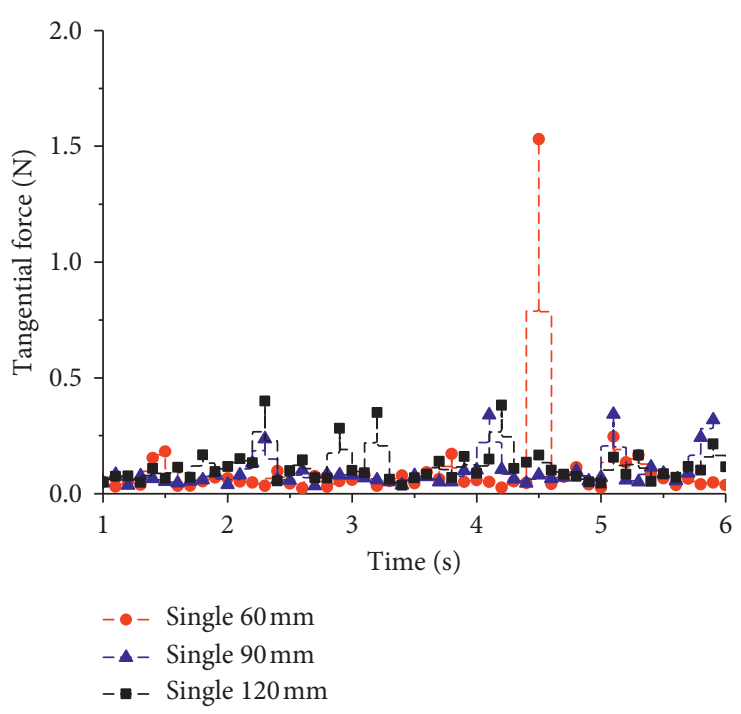

(b)

Figure 4: The contact force between particles at three different speeds in the single-flight screw feeder. 


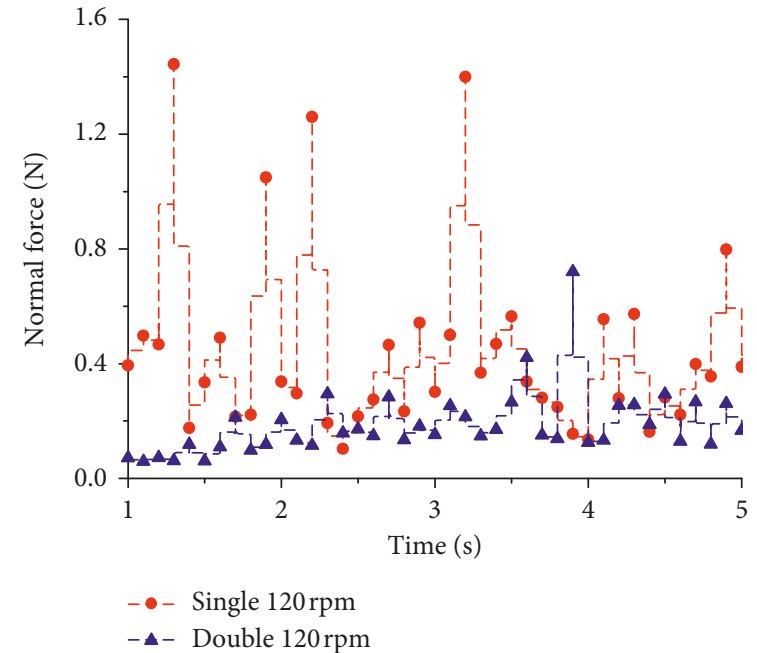

(a)

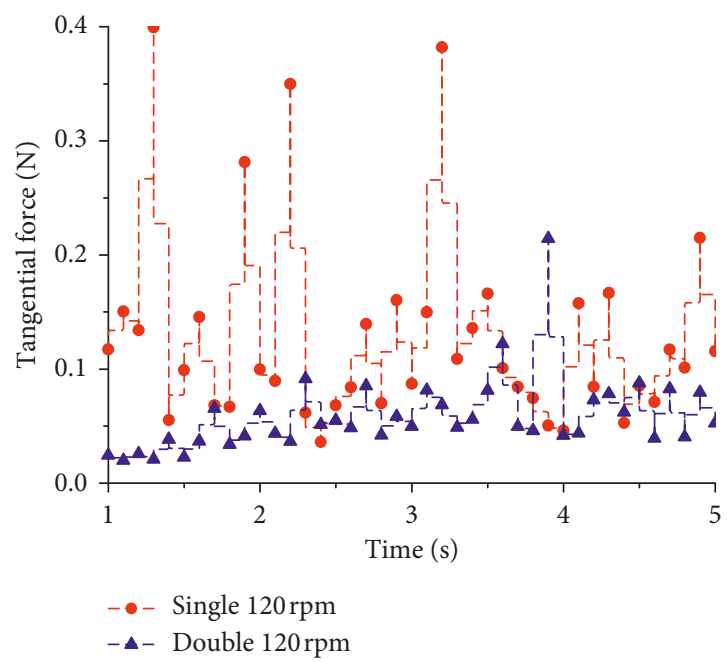

(b)

Figure 5: The contact force between particles in the single/double-flight screw feeders.

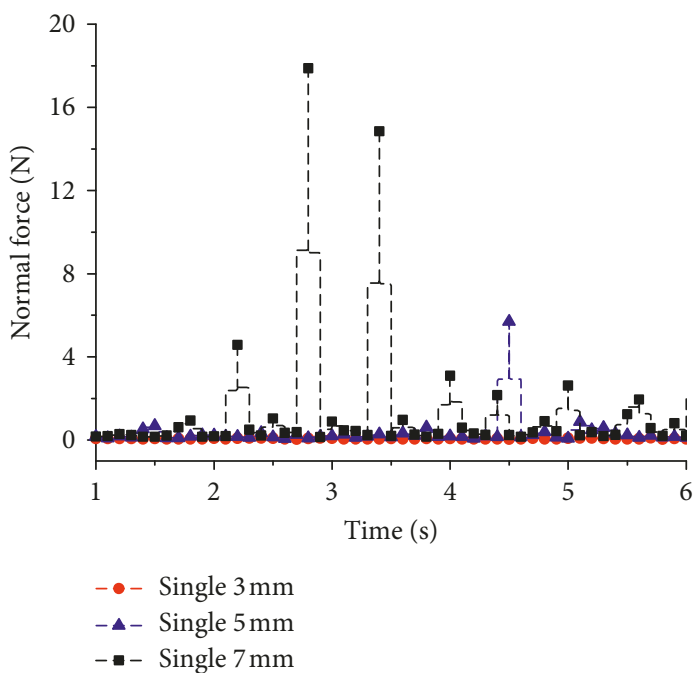

(a)

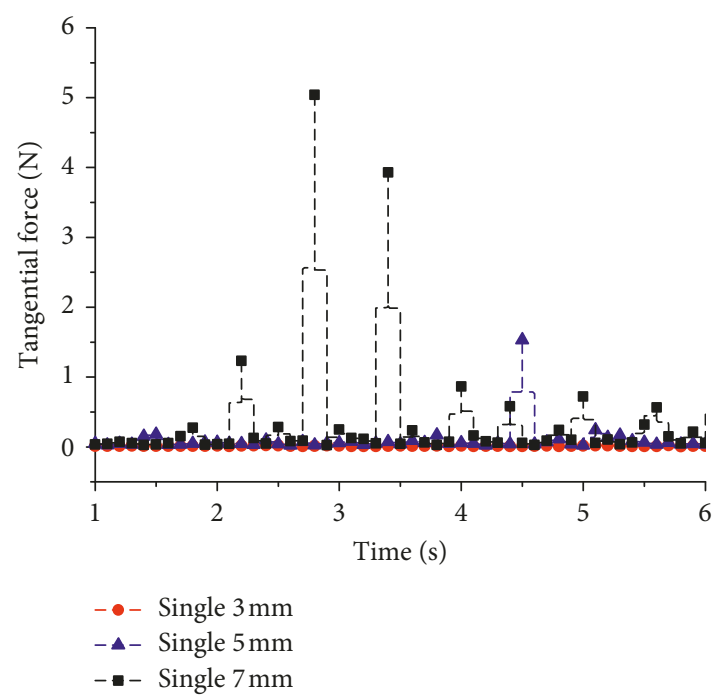

(b)

Figure 6: The contact force between particles with three different diameters in the single-flight screw feeder.

smaller size of bulk material, or smaller pitch should be chosen.

\section{Conflicts of Interest}

The authors declare that they have no conflicts of interest.

\section{Acknowledgments}

This work was supported by the National Natural Science Foundation of China (51175230) and the Innovation Project for Graduate Student Research of Jiangsu Province (KYLX_1019).

\section{References}

[1] U. Sander and K. Schonert, "Operational conditions of a screw-feeder-equipped high-pressure roller mill," Powder Technology, vol. 105, no. 1-3, pp. 282-287, 1999.

[2] P. A. Moysey and M. R. Thompson, "Modelling the solids inflow and solids conveying of single-screw extruders using the discrete element method," Powder Technology, vol. 153, no. 2, pp. 95-107, 2005.

[3] K. Uchida and K. Okamoto, "Measurement of powder flow in a screw feeder by x-ray penetration image analysis," Measurement Science and Technology, vol. 17, no. 2, pp. 419-426, 2006.

[4] K. Uchida and K. Okamoto, "Measurement technique on the diffusion coefficient of powder flow in a screw feeder by X-ray 
visualization," Powder Technology, vol. 187, no. 2, pp. 138-145, 2008.

[5] W. R. Ketterhagen, J. S. Curtis, C. R. Wassgren, and B. C. Hancock, "Predicting the flow mode from hoppers using the discrete element method," Powder Technology, vol. 195, no. 1, pp. 1-10, 2009.

[6] M. E. Zamiralova and G. Lodewijks, "Measurement of a pipe belt conveyor contact forces and cross section deformation by means of the six-point pipe belt stiffness testing device," Measurement, vol. 70, pp. 232-246, 2015.

[7] Q. J. Zheng, H. P. Zhu, and A. B. Yu, "Finite element analysis of the rolling friction of a viscous particle on a rigid plane," Powder Technology, vol. 207, no. 1-3, pp. 401-406, 2011.

[8] Q. J. Zheng, H. P. Zhu, and A. B. Yu, "Finite element analysis of the contact forces between a viscoelastic sphere and rigid plane," Powder Technology, vol. 226, pp. 130-142, 2012.

[9] Q. J. Zheng, Z. Y. Zhou, and A. B. Yu, "Contact forces between viscoelastic ellipsoidal particles," Powder Technology, vol. 248, pp. 25-33, 2013.

[10] J. W. Fernandez, P. W. Cleary, and W. McBride, "Effect of screw design on hopper drawdown of spherical particles in a horizontal screw feeder," Chemical Engineering Science, vol. 66, no. 22, pp. 5585-5601, 2011.

[11] Y. Yang and Y. M. Cheng, "A fractal model of contact force distribution and the unified coordination distribution for crushable granular materials under confined compression," Powder Technology, vol. 279, pp. 1-9, 2015.

[12] D. Jianjun and J. R. Grace, "A model for biomass screw feeding," Powder Technology, vol. 186, no. 1, pp. 40-55, 2008.

[13] P. W. Cleary, "Large scale industrial DEM modeling," Engineering Computations, vol. 21, no. 2-4, pp. 169-204, 2004.

[14] P. J. Owen and P. W. Cleary, "Prediction of screw conveyor performance using the Discrete Element Method (DEM)," Powder Technology, vol. 193, no. 3, pp. 274-288, 2009.

[15] Q. F. Hou, K. J. Dong, and A. B. Yu, "DEM study of the flow of cohesive particles in a screw feeder," Powder Technology, vol. 256, pp. 529-539, 2014.

[16] H. Hertz, "Ueber die Berührung fester elastischer Körper," Journal Für Die Reine Und Angewandte Mathematik, vol. 1882 , no. 92 , p. 71, 1882.

[17] R. D. Mindlin and H. Deresiewicz, "Elastic spheres in contact under varying oblique forces," Journal of Applied Mechanics, vol. 20, no. 3, pp. 327-344, 1953.

[18] Y. Tsuji, T. Tanaka, and T. Ishida, "Lagrangian numerical simulation of plug flow of cohesionless particles in a horizontal pipe," Powder Technology, vol. 71, no. 3, pp. 239-250, 1992.

[19] L. Vu-Quoc and X. Zhang, "An accurate and efficient tangential force-displacement model for elastic frictional contact in particle-flow simulations," Mechanics of Materials, vol. 31, no. 4, pp. 235-269, 1999.

[20] C. S. Chou, A. F. Lee, and C. H. Yeh, "Gas-solid flow in a twodimensional cross-flow moving granular filter bed with a symmetric boundary," Particle \& Particle Systems Characterization, vol. 24, no. 3, pp. 210-222, 2007.

[21] G. M. Hu, Discrete Element Method for Particle System Analysis and Simulation, Wuhan University of Technology press, Wuhan, Hubei, China, 2010.

[22] X. L. Zhang, K. Ma, H. Wang et al., "Effect of particle size on precision dosing of screw feeder," Transations of the Chinese Society of Agricultural Engineering, vol. 30, pp. 19-27, 2014. 


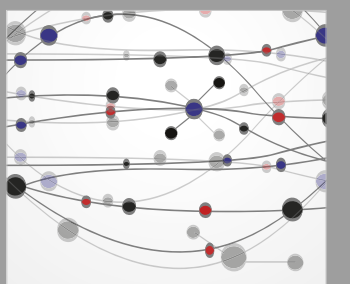

The Scientific World Journal
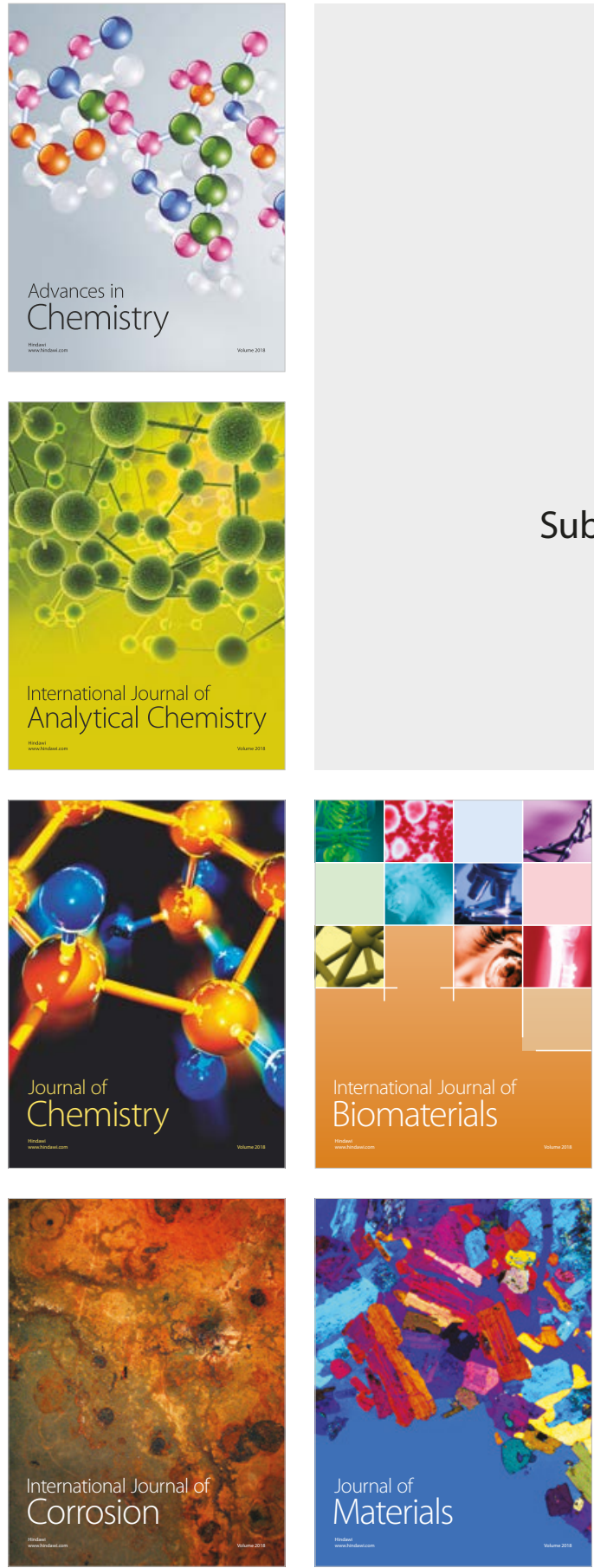

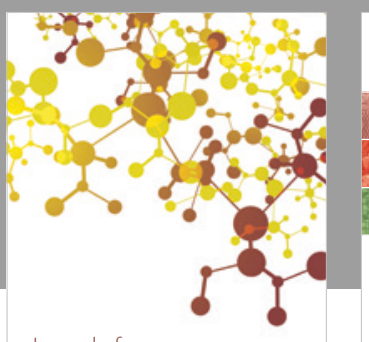

Journal of

Applied Chemistry
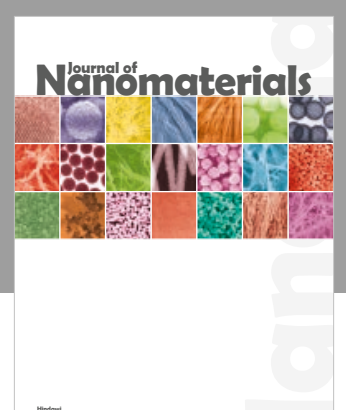

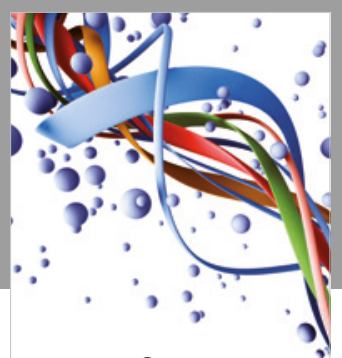

Scientifica

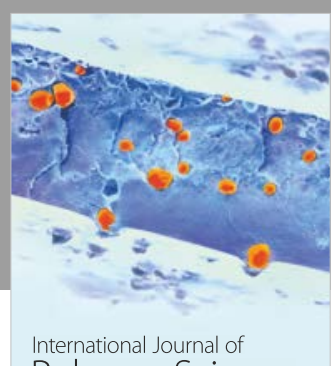

Polymer Science

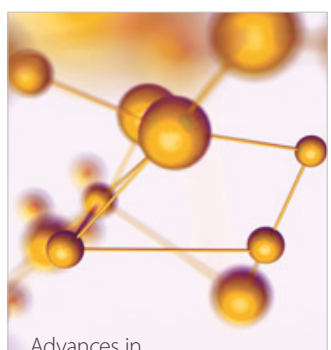

Physical Chemistry
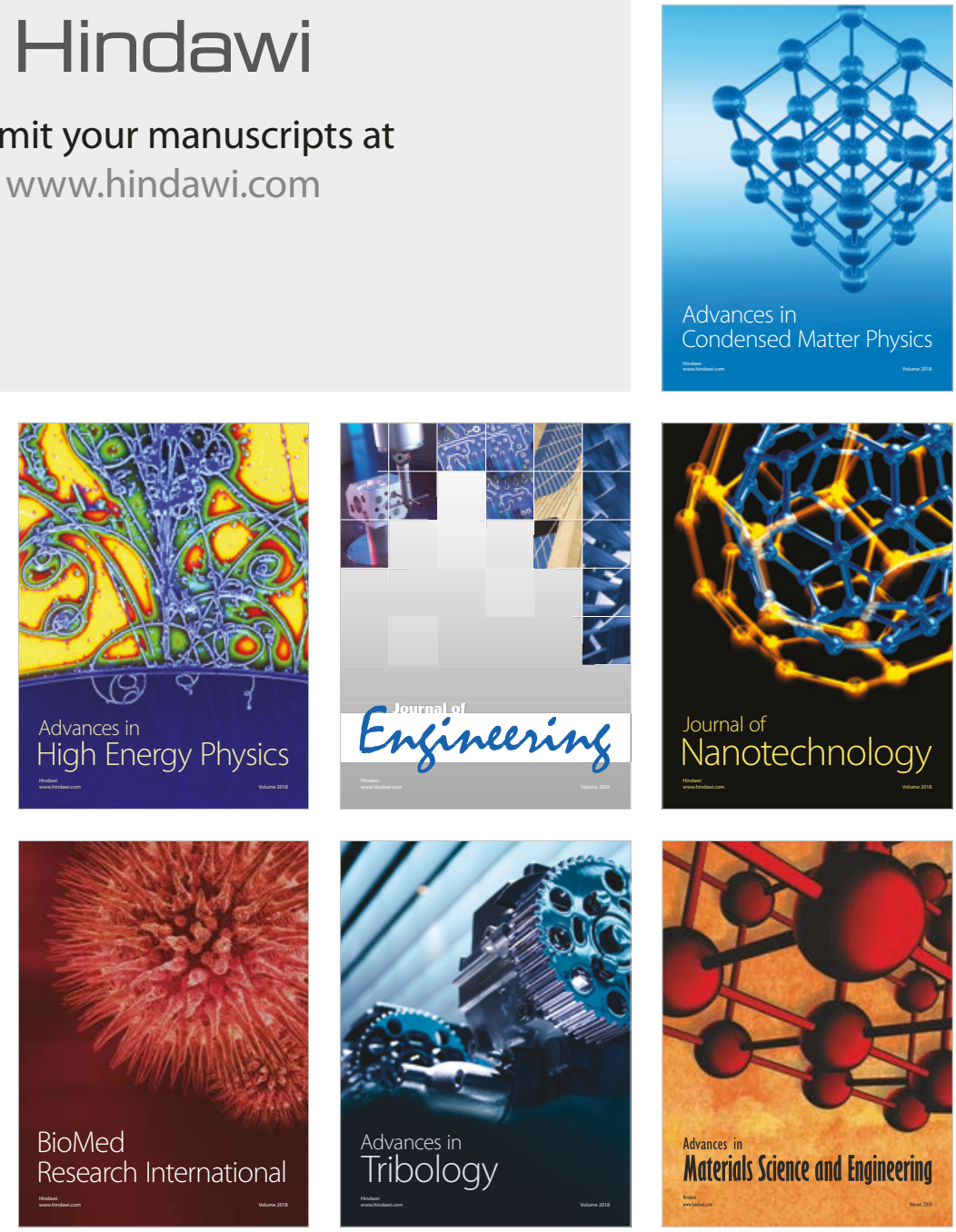